\title{
ANTIOXIDANT POTENTIAL OF MEDICINAL HERBS FROM THE NORTHERN BLACK SEA COASTAL ZONES
}

\author{
Ivanova D., Y. Kiselova-Kaneva, D. Ivanov* \\ Department of Biochemistry, Molecular Medicine and Nutrigenomics, *Department of Pharmacy, \\ Medical University "Prof. Dr. Paraskev Stoyanov" - Varna
}

Reviewed by: Assoc. Prof. T. Yankova

\begin{abstract}
Aqueous-alcoholic extracts of 32 plants used in Bulgarian phytotherapy for treatment of respiratory, gastrointestinal and other inflammatory disorders and widely distributed in the Northern Black Sea coastal zones were screened in vitro for antioxidant activity and phenolic compounds content. The antioxidant potential presented as UAE (Uric acid equivalents) of the plant extracts was determined using the ABTS cation radical decolorization method. The content of total polyphenols was measured spectrophotometrically according to the Folin-Ciocalteu procedure and calculated as quercetin equivalents $(\mathrm{QE})$. Four Bulgarian medicinal plants were established to have very high antioxidant properties: Fragaria vesca, Hypericum perforatum, Agrimonia eupatoria and Rubus sp. diversa) (UAE above $10 \mathrm{mM}$ ); another 10 plants had intermediate antioxidant capacity higher than 4mM; and other 5 - higher than $2 \mathrm{mM}$. Interestingly, those plants comprised $58 \%$ of all studied plant species and the high antioxidant potential of these medicinal plants could be a major factor contributing to their healing properties. Polyphenol content varied from 39,52 $\pm 15,17 \mu \mathrm{M}$ to 2930,70 $\pm 62,01 \mu \mathrm{M}$. A positive correlation $(r=0.98)$ between antioxidant activity and polyphenol content was found, suggesting that the antioxidant capacity of the aqueous-alcoholic plant extracts is mainly due to their polyphenol content.
\end{abstract}

Key words: Bulgarian medicinal plants, aqueous-alcoholic extracts, antioxidant activity, total polyphenol content

\section{INTRODUCTION}

Medicinal plants, known also as medicinal herbs, include a variety of plants used in medicinal or veterinary practice for prophylaxis and treatment of diseases - generally the term "medicinal plant" refers to the application of a plant. They are also often known as drug- or poison- plants since the medical usefulness is often only a matter of the dilution factor in which the active ingredient is introduced into or onto the human body. Since thousands of years ago people were apparently aware of hundreds of medically active compounds that were directly derived from plants. Such biologically active compounds from plant origin may range from alkaloids to glycosides, vitamins, waxes, tanning matters, essential oils, coumarins, lipids, pigments, saponins, phytoncides, or flavonoids. A number of medicinal plants are recognized nowadays as functional foods, food additives and a source for nutraceuticals, because of their active ingredients, and others are used by the pharmaceutical and cosmetic industries.

Medicinal properties of plants are often described as anti-inflammatory, bactericide, bacteriostatic, immunostimulating

Address for correspondence:

D. Ivanova, Dept. Biochemistry, Molecular Medicine and Nutrigenomics, Prof. P. Stoyanov Varna University of Medicine, 55 Marin Drinov Str., BG-9002, Varna, Bulgaria

e-mail:divanova@mu-varna.bg or other, and are related to the induction of resistance to various inflammatory diseases - gastrointestinal, urinary tract infections, respiratory or skin diseases etc. Part of the medicinal herbs' properties are attributed to the antioxidant activities of their constituents, including vitamins $\mathrm{A}, \mathrm{C}$ and $\mathrm{E}$ and polyphenols and various concepts dominate assigning the biological activity of polyphenols to their properties as reducing agents, hydrogen donators, metal chelators and radical quenchers $(9,11)$ or immunostimulators $(1,2)$.

Despite the wide distribution of Bulgarian medicinal plants, only few recent systematic studies explore their antioxidant potential (6-8) and no investigation had been carried out since now on the distribution of plant species with high antioxidant properties. The present study aims at screening the in vitro antioxidant activity and polyphenol content of medicinal plants widely distributed in the Northern wet Black Sea regions and used in Bulgarian phytotherapy for treatment of respiratory, gastrointestinal and other inflammatory disorders.

\section{MATHERIALS AND METHODS}

\section{Plants}

Thirty two Bulgarian medicinal plants were selected based on two major criteria: (i) established wide everyday use by the Bulgarian population for treatment of inflammatory 
conditions of various etiology and (ii) distribution in the vicinity of the town of Varna and the Northern Black sea coastal zones (3-5). The plants available on the market without prescription (commercial products of "Thalloderma" Pharmaceutical Laboratories) were collected from the region in the summer of 2008.

\section{Plant extracts}

Plant extracts were prepared as described earlier (8), with variations in the solvent type and concentration. Briefly, $250 \mathrm{mg}$ dried plan material was blended into a fine powder and extracted 3 times ( $3 \mathrm{~min}$ each) with $40 \%(\mathrm{v} / \mathrm{v})$ ethanol/water. Plant material/solvent ratio was kept to $1: 20 \mathrm{w} / \mathrm{v}$ ( $0.250 \mathrm{~g}: 5 \mathrm{ml})$. The supernatants from each extraction step were combined $(3.5 \mathrm{ml}$ from the first step, $4.5 \mathrm{ml}$ from the second and $5 \mathrm{ml}$ from the third - $13 \mathrm{ml}$ totally) and were diluted with $40 \%(\mathrm{v} / \mathrm{v})$ ethanol/water to total volume of $25 \mathrm{ml}$. Antioxidant activity and total polyphenol content were measured in a clear filtrate.

\section{Antioxidant activity of plant extracts}

The antioxidant activity of plant extracts was determined by the ABTS (2,2'-azinobis (3- ethylbenzothiazoline- 6sulfonic acid)) radical decolorization assay (10). The extend of decolorization as percentage inhibition of the pre-formed ABTS+ radical cation, proportional to the concentration of antioxidants, was calculated relative to the reactivity of uric acid as a standart. Results are presented as meansuric acid equivalents (mM UAE) \pm S.D. (n, number of independent experiments $=3-6$ ). ABTS, uric acid and potassium persulfate were perchased from Aldrich Chemical Company, Inc., Milwaukee, USA. Measurements were performed using a Perkin Elmer spectrophotometer.

\section{Total polyphenol content}

Phenolic compounds were assayed, according to the spectrophotometric method of Singleton and Rossi (12). Samples (7 $\mu \mathrm{l}$, five replicates) were introduced into test tubes; $1000 \mu \mathrm{l}$ of Folin-Ciocalteu's reagent diluted ex tempore with distilled water I ratio $1: 10$, and $800 \mu 1 \mathrm{NaHCO}_{3}(7.5 \%)$ were added. The tubes were mixed and incubated at $60^{\circ} \mathrm{C}$ for $10 \mathrm{~min}$. Absorption at $760 \mathrm{~nm}$ was measured (Perkin Elmer spectrophotometer). The total phenolic content was expressed as means quercetin equivalents $(\mu \mathrm{M} \mathrm{QE}) \pm$ S.D. Quercetin and Folin-Ciocalteu's reagent were obtained from Sigma-Aldrich Chemie GmbH, Taufkirchen, Germany.

\section{RESULTS AND DISCUSSTION}

Measurements of antioxidant activity and polyphenol content of aqueous-alcoholic extracts demonstrated considerable variations within the plant species: from $0,28 \pm 0,16$ mM UAE for Humulus lupulus to $16,13 \pm 0,28 \mathrm{mM}$ for Fragaria vesca (Table 1). Similar variations were evident from our previous studies $(5,6)$ of water-phase antioxidant activity of medicinal plants. Totally, very high antioxidant properties were established for aqueous-ethanolic extracts of four Bulgarian medicinal plants: Fragaria vesca, Hypericum perforatum, Agrimonia eupatoria and Rubus sp. diversa) (UAE above $10 \mathrm{mM}$ ); another 10 plants had intermediate antioxidant capacity - higher than $4 \mathrm{mM}$; and other 5 - higher than $2 \mathrm{mM}$. Interestingly, those plants comprised as much as $58 \%$ of all studied plant species. The high antioxidant potential of these medicinal plants could be a major factor contributing to their healing properties.

There were variations in the polyphenol content as well: from 39,52 $\pm 15,17 \mu \mathrm{M}$ for Valeriana officinalis to 2930,70 $\pm 62,01 \mu \mathrm{M} \mathrm{QE}$ for Fragaria vesca, and the higher polyphenol concentrations were measured for the extracts with higher antioxidant activity. A positive correlation $(\mathrm{r}=0.98)$ between antioxidant activity and polyphenol content was found (Fig. 1), suggesting that the antioxidant capacity of the aqueous-alcoholic plant extracts is mainly due to their total polyphenol content. Similarly, a high positive correlation was established earlier for aqueous-methanolic extracts of 23 Bulgarian herbs (8) and for the water infusions of those plants $(6,7)$.

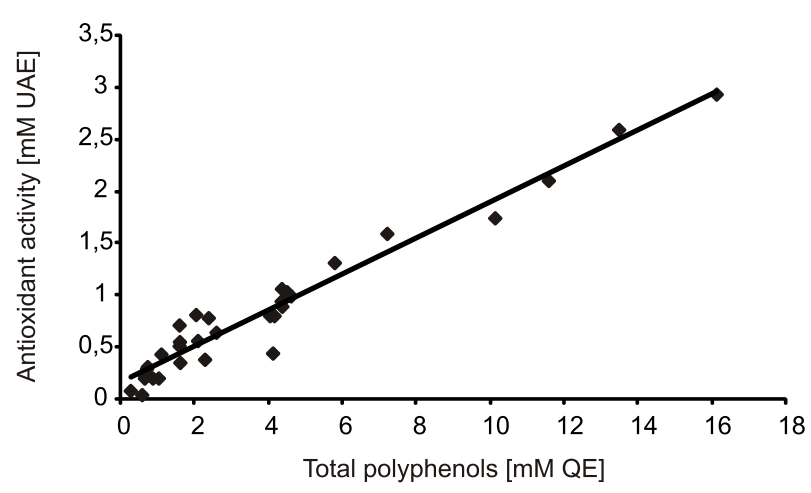

Fig. 1. Correlation between the antioxidant activity and total polyphenol content of aqueous-ethanolic extracts $(40 \%, v / v)$ of 32 medicinal plants from the Northern

\section{CONCLUSION}

Medicinal plants of North Black Sea coastal zones represent an excellent source of polyphenols with more than a half of all studied plant species exhibiting considerable antioxidant capacity. Our findings along with the numerous properties attributed to plant polyphenols give reason to suggest that the high polyphenol content of Bulgarian herbs is the major factor contributing to plants' healing properties.

\section{REFERENCES}

1. Brambilla, D., C. Mancuso, M. R. Scuderi, P. Bosco, G. Cantarella, L. Lempereur, G. Di Benedetto, S. Pezzino, R. Bernardini. The role of antioxidant supplement in immune system, neoplastic, and neurodegenerative disorders: a point of view for an assessment of the risk/benefit profile. Nutr. J., 30, 2008, 7-29. 
Antioxidant potential of medicinal herbs from the northern black sea coastal zones

2. Clarke, J.O., G. E. Mullin. A review of complementary and alternative approaches to immunomodulation. - Nutr. Clin. Pract., 23, 2008, 49-62.
3. Filipova-Marinova, M., D. Ivanov, D. Dimitrov. Flora und pflanzenwelt des Durankulak-Sees. -Bul. Mus. Nat. Varna, 30-31, 2000, 314-332.

Table 1. Antioxidant activity and total polyphenol content in aqueous-etahnolic extracts $(40 \%, v / v)$ of 32 medicinal plants from the Northern Black sea coastal zones.

\begin{tabular}{|c|c|c|c|}
\hline Plant name & Part of plant tested & $\begin{array}{c}\text { Antioxidant activity means } \pm \text { S.D. } \\
{[\text { [mM UAE] }}\end{array}$ & $\begin{array}{c}\text { Total polyphenols means } \\
\quad \pm \text { S.D. }[\mu \mathrm{M} Q \mathrm{QE}]\end{array}$ \\
\hline Fragaria vesca $\mathrm{L}$. & Leaves & $16,13 \pm 0,28$ & $2930,70 \pm 62,01$ \\
\hline Hypericum perforatum $\mathrm{L}$. & Aerial parts & $13,49 \pm 0,29$ & $2585,49 \pm 21,46$ \\
\hline Agrimonia eupatoria L. & Aerial parts & $11,59 \pm 0,29$ & $2095,11 \pm 52,13$ \\
\hline Rubus sp. diversa & Leaves & $10,14 \pm 0,28$ & $1741,94 \pm 43,26$ \\
\hline Sambucus ebulus L. & Fruits & $7,22 \pm 0,31$ & $1587,92 \pm 32,45$ \\
\hline Salvia officinalis L. & Leaves & $5,80 \pm 0,04$ & $1308,72 \pm 22,33$ \\
\hline Crataegus monogyna Jacq. & Leaves, flowers & $4,62 \pm 0,06$ & $985,13 \pm 40,21$ \\
\hline Frangula alnus Mill. & Roots & $4,51 \pm 0,32$ & $1033,71 \pm 207,02$ \\
\hline Sambucus nigra $\mathrm{L}$. & Flowers & $4,38 \pm 0,09$ & $893,88 \pm 108,53$ \\
\hline Crataegus monogyna Jacq. & Fruits & $4,37 \pm 0,05$ & $1058,60 \pm 41,25$ \\
\hline Populus alba L. & Leaves, flowers & $4,36 \pm 0,22$ & $940,01 \pm 22,33$ \\
\hline Polygonum aviculare (L.) L. & Aerial parts & $4,17 \pm 0,12$ & $801,02 \pm 34,14$ \\
\hline Arctium lappa $\mathrm{L}$. & Roots & $4,13 \pm 0,05$ & $440,06 \pm 127,99$ \\
\hline Helichrysum arenarium (L.) Moench. & Flowers & $4,05 \pm 0,82$ & $803,67 \pm 21,46$ \\
\hline Matricaria chamomilla L. & Flowers & $2,60 \pm 0,05$ & $639,92 \pm 25,10$ \\
\hline Pulmonaria officinalis L. & Leaves & $2,39 \pm 0,11$ & $782,43 \pm 24,53$ \\
\hline Asparagus officinalis L. & Aerial parts & $2,29 \pm 0,15$ & $378,55 \pm 52,92$ \\
\hline Achillea millefolium $\mathrm{L}$. & Flowers & $2,10 \pm 0,02$ & $558,49 \pm 108,97$ \\
\hline Taraxacum officinalis L. & Aerial parts & $2,05 \pm 0,11$ & $805,62 \pm 114,44$ \\
\hline Plantago mayor L. & Leaves & $1,60 \pm 0,14$ & $508,92 \pm 45,17$ \\
\hline Apium graveolens L. & Leaves & $1,62 \pm 0,06$ & $348,70 \pm 74,92$ \\
\hline Mentha spicata L. & Leaves & $1,61 \pm 0,02$ & $546,98 \pm 61,33$ \\
\hline Verbena officinallis L. & Aerial parts & $1,60 \pm 0,08$ & $710,02 \pm 67,67$ \\
\hline Galega officinallis L. & Aerial parts & $1,11 \pm 0,02$ & $426,77 \pm 64,39$ \\
\hline Urtica dioeica $\mathrm{L}$. & Leaves & $1,04 \pm 0,13$ & $204,03 \pm 54,00$ \\
\hline Ononis spinosa L. & Roots & $0,88 \pm 0,03$ & $204,03 \pm 22,33$ \\
\hline Astragallus glycyphyllos L. & Aerial parts, fruits & $0,74 \pm 0,03$ & $308,16 \pm 15,33$ \\
\hline Prunus spiniosa $\mathrm{L}$. & Fruits & $0,72 \pm 0,05$ & $293,82 \pm 42,93$ \\
\hline Capsella bursa-pastoris (L.) Medic. & Aerial parts & $0,66 \pm 0,05$ & $202,65 \pm 37,18$ \\
\hline Taraxacum officinalis L. & Roots & $0,64 \pm 0,02$ & $243,01 \pm 140,70$ \\
\hline Valeriana officinalis L. & Roots & $0,59 \pm 0,04$ & $39,52 \pm 15,17$ \\
\hline Humulus lupulus L. & Flowers & $0,28 \pm 0,16$ & $78,73 \pm 50,20$ \\
\hline
\end{tabular}


4. Filipova-Marinova, M., D. Ivanov, D. Dimitrov. Flora and vegetation of the area of the Shabla and Ezeretz lakes. -Bul. Mus. Nat. Varna, 32-33, 2002, 341 - 364.

5. Ivanov, D., M. Filipova-Marinova, D. Dimitrov. Flora and vegetation of the Nature Complex "Kamchia". -Ann. Sofia Univ., Book 2 - Botany, 92, 2002, 39-67.

6. Ivanova, D., D. Gerova, T. Chervenkov, T. Yankova. Polyphenols and antioxidant capacity of Bulgarian medicinal plants. -J. Ethnopharmacol., 96, 2005, 145-150.

7. Kiselova, Y., D. Ivanova, T. Chervenkov, D. Gerova, B. Galunska, T. Yankova. Correlation between the in vitro antioxidant activity and polyphenol content of aqueous extracts from Bulgarian herbs. - Phytother. Res., 20, 2006, 961-965.

8. Kiselova, Y., D. Ivanova, B. Galunska B., T. Chervenkov, D. Gerova, T. Yankova.
Polyphenol content and in vitro antioxidant activity of aqueous-alchoholic extracts from Bulgarian herbs. -Bull. Med. Inst. Mehrabyan, 1, 2006, 78-83.

9. More1, I., G. Lescoat, P. Cillard, J. Cillard. Role of flavonoids and iron chelation in antioxidant action. -Methods Enzymol., 234, 1994, 437-443.

10. Re, R., N. Pellegrini, A. Proteggente, A. Pannala, M. Yang, C. Rice-Evans. Antioxidant activity applying an improved ABTS radical cation decolorization assay. -Free Rad. Biol. Med., 26, 1999, 1231-1237.

11. Rice-Evans, C.A., N.J. Miller, G. Paganga. Antioxidant properties of phenolic compounds.

-Trends Plant Sci., 2, 1997, 152-159.

12. Singleton, V.L., J.A. Rossi. Colorimetry of total phenolics with phosphomolybdic-phosphotungstic acid reagents. -Am. J. Enol. Viticult., 16, 1965, 144-158. 